\title{
POBREZA E DESIGUALDADE NO SERTÃO SEMIÁRIDO DA BAHIA:UMA EXPLICAÇÃO A PARTIR DA ANÁLISE SOCIOAMBIENTAL DA DESERTIFICAÇÃO NO PÓLO DEJEREMOABO Carine Fonseca Menezes Silva ${ }^{1}$; Nacelice Barbosa Freitas ${ }^{2}$;
}

1. Bolsista PIBIC/FAPESB, Graduando em bacharelado em Geografia, Universidade Estadual de Feira de Santana, e-mail: carinemeneze@gmail.com

2. Orientadora, Departamento de Ciências Humanas e Filosofia, Universidade Estadual de Feira de Santana, e-mail: nacegeografic@hotmail.com

PALAVRAS-CHAVE: Desertificação; Desigualdade; Pólo de Jeremoabo.

\section{INTRODUÇÃO}

A Convenção das Nações Unidas de Combate à Desertificação (CCD), indica que em climas áridos, semiáridos e sub-úmidos secos ocorre o processo de desertificação, provocado pela degradação ambiental. Este processo resulta da ação de diversos fatores, tais como, as formas inadequadas de uso e manejo do solo, nas atividades agrícolas, tais como desmatamento, queimadas entre outros.

A Região Nordeste ocupa aproximadamente uma área de $1.556 .000 \mathrm{~km}^{2}$ do território nacional, e caracteriza-se pela diversidade socioambiental decorrentes das condições naturais, apresentando clima tropical úmido, tropical subúmido, e semiárido. O sertão ocupa aproximadamente $11,5 \%$ da extensão territorial do Brasil, e devido à relação sociedade e natureza, associado ao baixo nível técnico aplicado as práticas agrícolas, diversas áreas encontram-se suscetíveis ao processo de desertificação.

O texto tem por objetivo analisar a desigualdade na distribuição de renda do semiárido baiano, a partir dos dados obtidos durante a pesquisa de iniciação científica, tomando como referência a Incidência de Pobreza o Índice de Gini, e o Produto Interno Bruto dos municípios do Pólo de Jeremoabo, explicando a relação entre a vulnerabilidade ambiental ao processo de desertificação, e a qualidade de vida da população local.

\section{MATERIAL E MÉTODOS}

O resumo é resultado da pesquisa voluntária de iniciação científica, realizou-se um levantamento bibliográfico, visando a discussão sobre desertificação, semiárido, indicadores socioeconômicos e em seguida organizou-se os dados socioeconômicos em tabelas e gráficos para posteriormente mapear com a utilização do Sistema de Informações Geográficas (SIG). Para a elaboração dos mapas utilizou-se o software Arc View para o processamento de dados vetoriais e introdução dos dados tabulares e o Arc Map. Tal etapa possibilitou ter uma visão ampla da área de estudo, ao relacionar o mapeamento da mesma à da evolução dos números e correlacionar as informações obtidas ao conceito de qualidade de vida em área susceptível a desertificação. As etapas definidas para o desenvolvimento da pesquisa visam contribuir com o estudo dos indicadores socioeconômicos no Pólo de Jeremoabo - BA, possibilitando uma explicação sobre a realidade socioambiental e territorial.

As regiões semiáridas segundo Silva (2007) são caracterizadas, pela semiaridez do clima, deficiência hídrica com imprevisibilidade das precipitações pluviométricas, e pela presença de solos pobres em matéria orgânica, enquanto a semiaridez sazonal é resultado do prolongado período seco anual que eleva a temperatura local. O sertão ocupa aproximadamente $11,5 \%$ da extensão territorial do Brasil, e devido à relação sociedade e natureza, associado ao baixo nível técnico aplicado as práticas agrícolas, diversas áreas encontram-se suscetíveis ao processo de desertificação. De acordo com o texto da EMBRAPA (2010) grande parte da população residente na Região Nordeste está diretamente vinculada a atividades agropastoris, 
buscando o sustento a partir dos recursos naturais existentes. Contudo, tais atividades são dependentes da chuva e, em razão das adversidades, e a vulnerabilidade ao processo de desertificação, resulta em forte degradação ambiental, realidade esta dos municípios do Pólo de Jeremoabo.

O Pólo de Jeremoabo localizado no semiárido baiano é composto por treze municípios: Antas, Canudos, Chorrochó, Coronel João Sá, Glória, Jeremoabo, Macururé, Novo Triunfo, Paulo Afonso, Pedro Alexandre, Rodelas, Santa Brígida, e Uauá. Estes apresentam vulnerabilidade socioambiental estando propensos a desertificação. MAPA 1

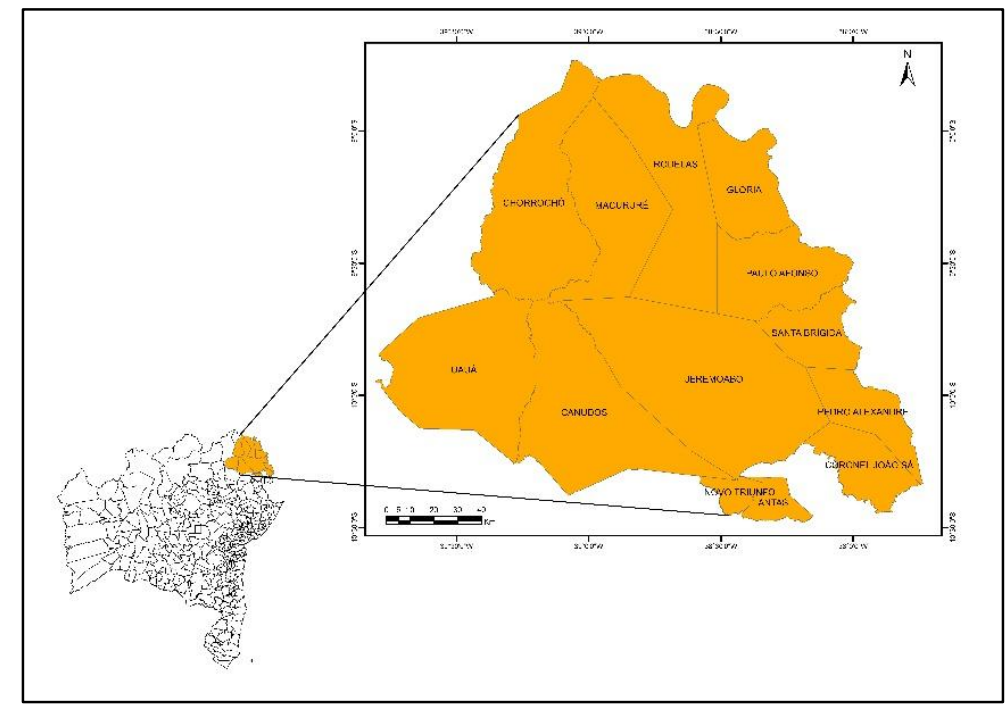

Mapa 1 - Localização do Pólo de Jeremoabo no estado da Bahia.

\section{RESULTADOS E/OU DISCUSSÃO}

A análise da pobreza e desigualdade e do Produto Interno Bruto permitiu explicar a relação entre a evolução dos mesmos e o processo de desertificação nos municípios do Pólo de Jeremoabo, visto que os as informações socioeconômicas refletem a realidade socioespacial.

Os municípios do Pólo de Jeremoabo estão inseridos na região semiárida da Bahia, em meio as relações conflituosas e de poder, onde os interesses das elites prevalecem sobre os interesses socioespaciais. A população total dos municípios, segundo os dados do censo demográfico do Instituto Brasileiro de Geografia e Estatísticas (IBGE-2010), corresponde a aproximadamente 309 mil habitantes. A população rural registra cerca de 130 mil habitantes, representando $43 \%$ da população total, enquanto a população urbana representa $57 \%$, somando mais de 174 mil habitantes.

A distribuição espacial da população dos municípios do Pólo de Jeremoabo é irregular, pois, enquanto Paulo Afonso, Jeremoabo e Uauá concentram 56\% da população total do Pólo, Rodelas, Macururé, e Chorrochó concentram $8 \%$ da população. As características sociodemográficas dos municípios demonstram que o processo de desertificação interfere na distribuição espacial da população, e contribui para o crescimento das desigualdades socioespaciais entre os municípios.

A degradação do solo pelo uso intensivo, o desmatamento, as queimadas e as práticas inadequadas na agricultura nos municípios, contribuíram para estabelecer a vulnerabilidade ambiental, tornando-os susceptíveis ao processo de desertificação, consequentemente há perda da potencialidade agrícola do solo, resultando no declínio da produtividade e isso é perceptível quando realizou-se o levantamento de dados sobre o PIB municipal entre 2000 a 2010.

A desertificação é uma problemática que atinge os municípios do Pólo, assim o setor da agropecuária é o de menor contribuição para o PIB do Pólo de Jeremoabo. Os setores do serviço 
e da indústria movem a economia da região, porém não são todos os municípios que possuem estrutura para comportar indústrias, por exemplo, que também poderia contribuir para a contaminação do solo, e da água.

Segundo o texto do Instituto de Pesquisas e Estratégia Econômica do Ceará (IPECE,2000) por definição, índice (ou coeficiente) de Gini é uma relação entre a área da desigualdade, indicada por $\alpha$ e a área do triângulo. Assim sendo: $20,5 \mathrm{G} \alpha==\alpha$.

Perceba que a perfeita igualdade implica que a área de $45^{\circ}$,ou seja a curva de lorenz e no caso de máxima desigualdade (pelo menos um $\mathrm{Xi}>0$ ) a Curva de Lorenz está sobreposta ao eixo horizontal até o último elemento que tem renda positiva. Assim os limites do Índice de Gini são $0 \leq \mathrm{G}<1$. Quanto mais os valores do coeficiente de Gini, se afastarem de 0 , maior será a desigualdade. O coeficiente de Gini pode ser usado para ajudar a quantificar as diferenças no bem-estar e de concepções políticas e filosóficas de alguns países. Tabela 1.

Tabela 1.Incidência da Pobreza e Índice de Gini do Pólo de Jeremoabo 2003 (\%)

\begin{tabular}{lll} 
Municípios & Incidência de Pobreza & Índice de Gini \\
\hline Antas & 41,11 & 0,41 \\
Canudos & 52,52 & 0,41 \\
Chorrochó & 29,15 & 0,36 \\
Coronel João Sá & 56,67 & 0,36 \\
Glória & 45,82 & 0,38 \\
Jeremoabo & 48,9 & 0,39 \\
Macururé & 38,0 & 0,38 \\
Novo Triunfo & 42,45 & 0,36 \\
Paulo Afonso & 42,01 & 0,5 \\
Pedro Alexandre & 48,22 & 0,35 \\
Rodelas & 38,93 & 0,43 \\
Santa Brígida & 28,22 & 0,35 \\
Uauá & 44,98 & 0,42 \\
\hline
\end{tabular}

Fonte: Instituto Brasileiro de Geografia e Estatística (IBGE-2010)

O coeficiente de GINI é uma medida de desigualdade calculada por meio de uma análise de razão, ao invés de uma variável representativa da maioria da população, tais como renda per capita ou do produto interno bruto. Ele pode ser usado também para comparar as distribuições de renda entre diferentes setores da população, tais como espaço urbano e rural.

A definição de pobreza está relacionada a algum tipo de privação cuja natureza pode ser absoluta, relativa ou subjetiva, dadas as carências de ordem material, cultural e social, em face à disponibilidade e ao usufruto de recursos de um indivíduo ou de um grupo social (Kageyama; Hollfmann, 2006). Nessa perspectiva, define-se a pobreza por meio de três categorias: a pobreza absoluta, a relativa e a subjetiva, associadas, respectivamente, à não satisfação de um mínimo definido socialmente, à privação de bens e serviços considerados comuns numa sociedade e ao sentimento de impotência.

Analisando o Índice de Gini percebe-se que o município de Rodelas registra o maior índice do Pólo de Jeremoabo, configurando-se como o município mais desigual na distribuição de renda. Em 2010, segundo o IBGE o rendimento médio mensal urbano do município registrou valor de $\mathrm{R} \$ 1.066,00$ (mil e sessenta e seis reais), enquanto o do espaço rural $\mathrm{R} \$ 810,33$ (oitocentos e trinta e três reais). O Produto Interno Bruto de Rodelas apresentou no ano de 2000 
o valor de $\mathrm{R} \$ 7.243,00$ (sete mil, duzentos e quarenta e três reais), e no ano de 2010 o valor de $\mathrm{R} \$ 36.637,00$ (trinta e seis mil, seiscentos e trinta e sete reais). Paulo Afonso apresenta o menor Índice de Gini do Pólo com 0,5 indicando uma menor desigualdade de renda. O município de Coronel João Sá é apresenta a maior incidência de pobreza do Pólo, enquanto Santa Brígida registra configura-se como o município com menor incidência de pobreza.

As disparidade de de renda e o desenvolvimento territorial desigual surgem enquanto evidências da concentração econômica e espacial do processo de desenvolvimento do país. São estes elementos que expressam o relativo atraso social e econômico, haja vista as diferenças entre as condições socioeconômicas das regiões e classes sociais.

O Pólo de Jeremoabo reflete as consequências do processo de desertificação e a falta de planejamento em uma desigualdade na distribuição de renda, na distribuição socioespacial da população, e nos indicadores socioeconômicos. Para a redução na incidência da pobreza faz-se necessário uma redução no grau de desigualdade, o que permite uma elevação da renda e a melhoria da qualidade de vida população que ali reside. O Pólo é constituído por treze municípios, que compartilham das mesmas características geográficas, e suscetibilidade ambiental, o que difere os mesmos são as características históricas, as gestões municipais, a dinâmica e o perfil sociodemográfico e socioeconômico. Porém as desigualdades apresentadas explicam a realidade do semiárido baiano, justificando a necessidade do planejamento e ordenamento territorial para os municípios do Pólo de Jeremoabo.

\section{CONSIDERAÇÕES FINAIS}

A necessidade de um planejamento para os municípios da região semiárida da Bahia denota da precariedade das condições de vida da população, as intervenções do estado na região do Pólo de Jeremoabo não atendeu as demandas da população de forma efetiva, pois ao invés de subsidiar e oferecer infraestrutura aos habitantes dos municípios do Pólo de Jeremoabo, as ações e intervenções do estado beneficiam os interesses do capital contribuindo para o agravamento das consequências da desertificação, e acentuando as desigualdades socioeconômicas dos municípios do Pólo, surgindo assim a necessidade do ordenamento territorial visando à melhoria da qualidade de vida da população.

$\mathrm{O}$ ordenamento territorial é um instrumento que objetiva o planejamento integrado e espacializado da ação do poder público. Assim o estado deve atuar como um agente regulador e harmonizador, das demandas locais/regionais. O Plano Nacional de Ordenamento Territorial (PNOT) discute que o principal objetivo do Ordenamento Territorial é a implementação de um planejamento territorial que vise a redução das desigualdades regionais e ao fortalecimento da coesão territorial pelo uso racional dos recursos e das potencialidades de cada região, afirmando as identidades e fortalecendo a capacidade regional de construir o futuro. Dessa forma, o ordenamento territorial é uma importante ferramenta na superação das desigualdades existentes do Pólo, já que seu objetivo é a orientação para um planejamento integrado do espaço, considerando a ampla diversidade de elementos, sejam: físicos, humanos ou biológicos, que caracterizam o território.

\section{REFERÊNCIAS}

AB'SÁBER, A. Os domínios de natureza no Brasil: potencialidades paisagísticas. São Paulo: Ateliê Editorial, 2003.

IPECE,2010. Instituto de Pesquisa e Estratégia Econômica do Ceará.

KAGEYAMA, Ângela; HOFFMANN, Rodolfo. Pobreza no Brasil: uma perspectiva multidimensional. Revista Economia e Sociedade. Campinas: v.15, n.1(26), p. 79-112, janjun/ 06.

SILVA, Roberto Marinho Alves da. Revista Econômica do Nordeste, Fortaleza, v. 38, n 3, jul-set. 2007. 